\title{
CPI Mismeasurements and Their Impacts on Economic Management in Korea*
}

\section{Chul Chung \\ Korea International Trade Association \\ Washington, DC 20036 \\ USA \\ and Korea Institute for \\ International Economic Policy \\ Seoul 137-747, Korea \\ cchung@kita.net}

\section{John Gibson}

Department of Economics

University of Waikato

Private Bag 3105

Hamilton, New Zealand

jkgibson@waikato.ac.nz

\section{Bonggeun Kim}

Department of Economics

Seoul National University

599 Gwanak-no, Gwanak-gu

Seoul I5I-746, Korea

bgkim07@snu.ac.kr

\begin{abstract}
We estimate the consumer price index (CPI) bias in Korea by employing the approach of Engel's Law as suggested by Hamilton (200 I). Using Korean panel data (Korean Labor and Income Panel Study) and following Hamilton's model with a non-linear specification correction, our estimation result shows that the CPI bias over the sample period (2000-05) averaged at least 0.7 percent annually, which implies that about 21 percent of the inflation rate during the sample period can be attributed to the bias. This CPI bias has caused a substantial understatement of the growth in real GDP and contributes to excessive transfers from younger taxpayers to the elderly through indexed pension payments. We discuss the implications of the CPI bias for economic management and policies in Korea.
\end{abstract}

\section{Introduction}

A consumer price index (CPI) measures the average price of consumer goods and services purchased by households. Inflation is measured by the percent change in the CPI, which is frequently used to index wages, pensions, social security payments, or long-term contracted prices. The $\mathrm{CPI}$ is also used to convert nominal variables to real ones such as real income and real economic growth by adjusting for the effects of inflation so that those nominal variables can be compared over time at the price level of the base year.

* We are grateful to Barry Bosworth, Prema-chandra Athukorala, Iris Claus, and the participarts in the 2008 Asian Economic Panel Meeting in Washington, DC, for their helpful comments. 
It is crucial to measure the CPI precisely for the accurate evaluation of a country's economic status and for international comparison. When there is a bias in the CPI, some macroeconomic variables can be miscalculated. Those miscalculated economic indicators may not reflect true conditions of the economy and consequently they may lead to imprudent economic policies possibly resulting in unintended transfers from one group to another group in the economy. For example, when there is an upward CPI bias and the public pension is indexed to the inflation rate, the government will inadvertently transfer resources from the younger generation to the older generation.

In this context, the U.S. Treasury welcomed the report by the U.S. Advisory Commission to study the CPI, known as the Boskin Report (1996), because many government social expenditures are tied to the inflation rate. The Boskin Report raised a great deal of attention from academic and policymaker circles to the long-standing debate of whether the cost-of-living index (COLI) should be the objective of measuring a price index. ${ }^{1}$

The CPI has four biases inherent in its calculation. They include (1) substitution bias, (2) quality change bias, (3) outlet substitution bias, and (4) new product bias. ${ }^{2}$ Because of these biases, the inflation rate derived from the (potentially biased) CPI tends to be overestimated and the CPI may not measure the true COLI. ${ }^{3}$ The Boskin Commission confirmed this by reporting that there was an overstatement of the annual inflation rate by about 1.1 percentage points. This implies that the U.S. real economic growth rates must have been higher than those recorded. The Boskin Report also calculated that the overstatement of inflation would add US\$ 148 billion to the deficit and US\$ 691 billion to the national debt by 2006. Accordingly, since 1999, the U.S. Bureau of Labor Statistics (BLS) has modified the CPI calculation method as suggested by the Boskin Report. Nevertheless, there is an ongoing debate in the

1 According to Reinsdorf and Triplett (2009), the history of evaluation of the conceptual foundations and methodologies of the CPI and price indexes in general dates back to more than 90 years.

2 The substation bias occurs when a Laspeyres type index does not recognize that consumers make economizing substitutions away from items that have become more expensive than they were in the base period when the CPI basket of goods was formed. The outlet bias is similar, with shoppers responding to lower prices by switching outlets while price surveyors do not. The quality change and new goods bias reflect the difficulty of measuring the declining cost of living when there are new and improved goods available, and this is accentuated when there is delayed introduction of new goods into the basket.

3 Not everyone is convinced that CPI bias always overstates the true change of prices, at least for some elements of the CPI. For example, Gordon and vanGoethem (2005) suggest that the CPI for rental housing in the United States, which is the most important single category of the overall CPI, has been downwardly biased for the last century. 
United States and in other countries about the continuing extent of the CPI bias problem.

This debate has been aided by a new approach to estimating the CPI bias using Engel curves, which were introduced by Hamilton (2001). The basis of the approach is that Engel's Law shows the inverse relationship between food's budget share and household real income. Because food's budget share may reflect real living standards, its movements can serve as an indicator of movements in real income. Therefore, Hamilton estimates the degree to which the CPI is biased by comparing the implied movements in real income that are inferred from movements in food's budget share with directly measured movements in real income that have nominal income deflated by the CPI. This method has an advantage over other approaches for the following three reasons. First, the relationship between food's budget share and household real income is one of the most established empirical regularities. Second, Engel curves should not drift over time if consumer preferences are stable. Third, any drift over time in the food Engel curve can be detected rather easily because as a necessity, food's demand is income inelastic and its budget share moves as real income changes by much more than the budget shares of goods with unitary income elasticities.

This paper builds on the work of Hamilton (2001) to investigate CPI mismeasurements in Korea using the Korea Labor Income Panel Survey (KLIPS) data from 2000-05. ${ }^{4}$ Further, we modify the Almost Ideal Demand System, which is widely used to estimate food demand, to a nonlinear functional form for more precise estimation of the CPI bias. Our results show that the CPI upward bias in Korea is at least 0.7 percent annually, which implies that about 21 percent of the inflation rate during the sample period can be attributed to the bias. With our estimated bias, we discuss its implications for economic management in Korea. For example, the CPI bias has caused undue transfers from the younger generation to the elderly through various indexed pension programs in Korea. We extend our discussion to incorporate changes in exchange rates. In doing so, we also confirm Gibson's (2008) finding of a substantial CPI bias in a small open economy, which is likely to be more responsive to trade shocks that result in volatile relative prices and a stronger substitution bias than occurs in large economies like the United States. Finally, we discuss the implications of the CPI bias for economic theories and policies related to business cycles and we conclude with our suggestions.

4 Chung, Kim, and Park (2007) is a first-ever attempt to estimate the Korean CPI bias. This paper refines its estimation method and investigates the implications of the CPI bias for economic management and policies in Korea. 
The structure of the paper is as follows. Section 2 describes the food Engel curve estimation method. We describe the KLIPS data and provide empirical results in section 3. Section 4 discusses implications of CPI bias for economic management in Korea, the relationship between being a small open economy and the size of the bias, and the implications of CPI bias for economic theories on business cycles.

\section{Engel curve method}

We adopt an empirical framework used in Hamilton (2001), Costa (2001), and Gibson, Stillman, and Le (2008) to measure CPI bias from a food Engel curve estimated on panel data. This method starts with the Leser-Working form of the Engel curve, where the budget share is a linear function of the logarithm of real household income and a relative price term: ${ }^{5}$

$$
w_{i, j, t}=\phi+\gamma\left(\ln P_{F, j, t}-\ln P_{N, j, t}\right)+\beta\left(\ln Y_{i, j, t}-\ln P_{j, t}\right)+\mathbf{X}^{\prime} \theta+u_{i, j, t},
$$

where $w_{i, j, t}$ is the budget share of food for household $i$ in region $j$ and time period $t$, $P_{F, j, t}, P_{N, j, t}$ and $P_{j, t}$ represent the true but unobserved prices of food, non-food, and all goods, $Y$ is the household's total income, $\mathbf{X}$ is a vector of individual household characteristics, and $u$ is the disturbance. The true cost of living is treated as a geometric weighted average of food and non-food prices:

$$
\ln P_{j, t}=\alpha_{t} \ln P_{F, j, t}+\left(1-\alpha_{t}\right) \ln P_{N, j, t}
$$

In addition, it is assumed that prices of a good $G$ (either food, non-food, or all goods) are measured with error, which is assumed not to vary geographically,

$$
\ln P_{G, j, t}=\ln P_{G, j, 0}+\ln \left(1+\Pi_{G, j, t}\right)+\ln \left(1+E_{G, t}\right)
$$

In equation (3), $\Pi_{G, j, t}$ represents the cumulative percentage increase in the true price of good $G$ from period zero to period $t$ and $E_{G, t}$ is the period- $t$ percent cumulative measurement error in the CPI since the base period. By inserting equations (2) and (3) into (1), we have:

$$
\begin{gathered}
w_{i, j, t}=\phi+\gamma\left[\pi_{F, j, t}-\pi_{N, j, t}\right]+\beta\left[y_{i, j, t}-\pi_{j, t}\right]+\mathbf{X}^{\prime} \theta \\
+\gamma\left[\boldsymbol{\epsilon}_{F, t}-\boldsymbol{\epsilon}_{N, t}\right]-\beta \boldsymbol{\epsilon}_{t}+\gamma\left(p_{F, j, 0}-p_{N, j, 0}\right)-\beta p_{j, 0}-u_{i, j, t}, \\
\ln \left(1+\Pi_{F, j, t}\right)=\pi_{F, j, t} \ln Y_{i, j, t}=y_{i, j, t}, \ln \left(1+E_{G, t}\right)=\epsilon_{G, t}, \ln P_{G, j, 0}=p_{G, j, 0}
\end{gathered}
$$

5 This functional form provides the basis of the Almost Ideal Demand System of Deaton and Muellbauer (1980). Results when a quadratic in log income is used are also described subsequently. 
An empirical version of equation (4) can be estimated if a database can be constructed from a panel household expenditure survey, and a temporal and crosssectional CPI for food, non-food, and all consumption:

$$
\begin{aligned}
w_{i, j, t} & =\hat{\phi}+\gamma\left[\pi_{F, j, t}-\pi_{N, j, t}\right]+\beta\left[y_{i, j, t}-\pi_{j, t}\right]+\mathbf{X}^{\prime} \theta \\
& +\sum_{t=1}^{T} \delta_{t} D_{t}+\sum_{j=1} \delta_{j} D_{j}+u_{i, j, t}
\end{aligned}
$$

where $D_{t}$ is a dummy variable equal to 1 in period $t, D_{j}$ is a dummy equal to 1 for region $j, \delta_{t}$ and $\delta_{j}$ are their coefficients, and $\hat{\phi}$ is the intercept from equation (4), plus the coefficients of the omitted time and region dummies. The time dummy variables are crucial to the measurement of CPI bias because

$$
\delta_{t}=\gamma\left(\epsilon_{F, t}-\epsilon_{N, t}\right)-\beta \epsilon_{t}
$$

If the CPI bias in food and non-food is equal, then Hamilton (2001) notes that equation (6) can be reduced to:

$$
\varepsilon_{t} \cong \frac{\delta_{t}}{-\beta}
$$

That is, the cumulative percentage CPI bias at period $t, E_{t}$, is given by a simple ratio of estimated coefficients from equation (5), $1-\exp \left(-\delta_{t} / \beta\right)$.

\section{Empirical analysis}

\section{I Data}

It is helpful to provide some background on how the CPI is constructed in Korea to better understand any CPI mismeasurements. ${ }^{6}$ The first CPI in Korea for the whole country, named the Whole Country Retail Price Index, was released in April 1949. The retail price index for Seoul was released earlier in 1936. Since 1990, the Korea National Statistical Office (KNSO) has produced and released the CPI in four different categories, such as the basic category, which is the traditional benchmark case classified by categories according to Classification of Individual Consumption by Purpose of the United Nations and three special categories, namely commodity property, fresh food, and purchasing frequency. The CPI started to include owneroccupied housing as a supplementary index in 1995.

The index was revised every five years to reflect the changes in consumption structure of urban households. In January 2002, the results of the revised index as of 2000

6 This section heavily depends on the information available at the KNSO's web site: www.nso.go.kr and the Korean CPI data can be downloaded from that source. 
were released. In April 2003, the nationwide chain index as of 2002 was released as a supplementary index. The indexes have been revised on a 5-year basis to reflect the changes in consumption structure of urban households. In December 2006, the results of revised indexes were released with 2005 prices based.

Year 2005 is the current base year for the Korean CPI. The Korean CPI is produced using prices of 489 items that have a higher than 1/10,000 share of the average urban household's monthly expenditure, worth 185 Korean won. Agricultural, fishery, and livestock products are surveyed three times per month on a weekday of three weeks, which contain the 5th, 14th, and 23rd day of the month. Meanwhile, information on industrial products is collected once a month on two weekdays of the week containing the 14th day of the month and service once a month on two weekdays of the week containing the 23rd day of the month.

KNSO officials, who visit approximately 21,000 retail stores and 10,000 renting households in 38 cities, conduct the survey. When some items have unusually high or low prices due to natural disasters, a store closing sale, bulk trading, and so on, they are excluded from the survey. The index is calculated on a monthly basis using the Laspeyres method and released in the first week of the next month.

The data used in this paper are drawn from KLIPS, which is an ongoing nationally representative longitudinal household survey fielded since 1998 by the Korea Labor Institute. KLIPS collects data on an exhaustive list of individual and household characteristics including detailed income and expenditure data. We use six rounds of KLIPS data from 2000 to 2005,7 and combine these with the annual CPI for food and non-food that is calculated for each of the 16 regions of Korea. We use a sample of two-adult families, which are headed by a man, with or without children, where the adults are between 20 and 65 years old, because more precise estimates of the under-reporting parameter may be obtained by focusing on a fairly homogeneous group. We drop the households which had experienced changes in their composition during the sample period to remove the effects of food consumption changes due to newly added members or exits of original members. We restrict attention to urban households, because measured food shares for rural households may be distorted if the survey has difficulty in capturing consumption from own production, which is likely to be more important in rural areas. The samples are further restricted to those households whose food-at-home shares are in the 0.01-0.99 interval. The resulting sample size is 5,134 households.

7 The collection of data on food expenditure at home starts only in 2000, so earlier waves of KLIPS data cannot be used in this study. 
Table 1. Descriptive statistics (KLIPS, 2000-05), obs. = 5,134

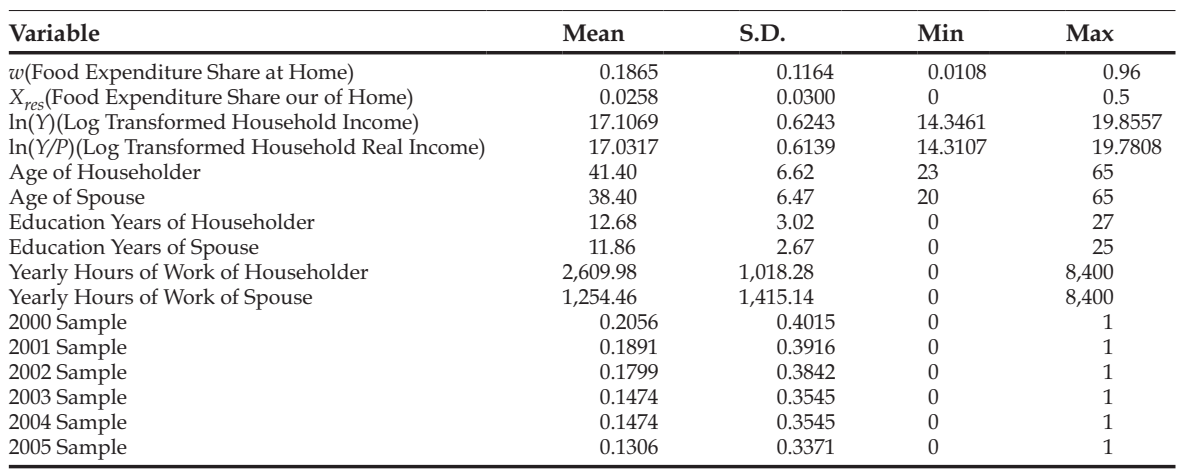

The dependent variable is the budget share for food consumed at home, and control variables include real total income (deflated by the CPI with a 2005 average base), relative food price changes, and demographic, educational, and employment characteristics. The model also includes the budget share for food out of the home. This form of consumption is not part of the dependent variable because it is assumed that restaurant meals are not perfect substitutes for food-at-home. Ideally, the substitution possibilities between restaurants and home cooking would be captured by including the relative price of restaurant meals, but this is not available. Therefore, we follow the practice in the literature that uses Engel curves to measure CPI bias, and we use the budget share for restaurant meals as an explanatory variable in place of the required price.

A description of the dependent and explanatory variables is shown in Table 1. The dependent variable, which is the expenditure share for food consumption at home, averages 18.6 percent for the sample period. Control variables include relative food price changes, demographic and educational characteristics, hours of work, and the expenditure share for food out of home. The share of food out of home averages 2.6 percent. Reported real total household income including labor income and financial income averages 3,400 million Korean won, which is approximately equal to US\$ 30,000 in 2003. On average, the household head is 41.4 years old and has 12.7 years of schooling whereas the spouse has 1 year less and is about 3 years younger.

To show how our main variables like food shares and household incomes have changed over time, the beginning-, middle-, and end-period averages of those variables are reported in Table 2. The first row of Table 2 shows that the average food-at- 
Table 2. Trend of main variables over time (KLIPS, 2000-05), obs. $=5,134$

\begin{tabular}{lccr}
\hline Variable & $\mathbf{2 0 0 0}$ & $\mathbf{2 0 0 3}$ & $\mathbf{2 0 0 5}$ \\
\hline$w$ (Food Expenditure Share at Home) & 0.2254 & 0.1776 & 0.1553 \\
$X_{\text {res }}$ (Food Expenditure Share out of Home) & 0.0264 & 0.0236 & 0.0241 \\
$\ln (Y$ (Log Transformed Household Income) & 16.885 & 17.176 & 17.319 \\
$\ln (Y / P)$ (Log Transformed Real Household Income & 16.885 & 17.076 & 17.157 \\
$P_{, t}$ (Consumer Price Index) & 1 & 1.105 & 1.176 \\
$P_{F j, t}$ (Food CPI) & 1 & 1.154 & 1.284 \\
$P_{N_{, t}, t}$ (Non-food CPI) & 1 & 1.087 & 1.146 \\
\hline
\end{tabular}

home share in Korea fell by about 7 percentage points from 22.5 percent in 2000 to 15.5 percent in 2005 . Over the same period, the CPI increased by 17 percent, nominal household income grew by 63 percent, and its real value adjusted by the CPI grew about 40 percent.

This fall in the food share is relative to the measured growth in real income, which is consistent with the existence of a substantial CPI bias in Korea. Figure 1 illustrates the persistent downward shift of Engel curves over the time. We attribute this downward shift to understated real income, which in turn is due to the overstated CPI.

\subsection{Estimation results}

The method we use, which follows several previous studies, is critically dependent on the assumption of stable consumer preferences over time. To provide some assurance that this assumption is reasonable we adopt several precautionary procedures, which advance those used in previous studies. First, we drop the households who had experienced changes in their composition during the sample period to remove the effects of food consumption changes due to newly added members or exits of original members. ${ }^{8}$ Second, we report results both in a linear and a quadratic form of log real income models. If the relationship is non-linear, then the linear model estimates in the previous studies will be biased due to an omitted variable bias and the resulting relationship could be time-varying due to the different level of real income over time. Third, because our data are a genuine panel we avoid potentially time-varying relationships caused by a different sample composition in each year (with potentially different consumption tastes), which could result if we had followed a common strategy in this literature of relying on repeated cross-sectional samples.

Equation (5) is estimated for a sample of two-adult families, with or without children, where the adults are between 20 and 65 years old and several other sample se-

8 This restriction removed approximately 10 percent of the sample. 
Figure 1. Downward shift of Engel curve (KLIPS)

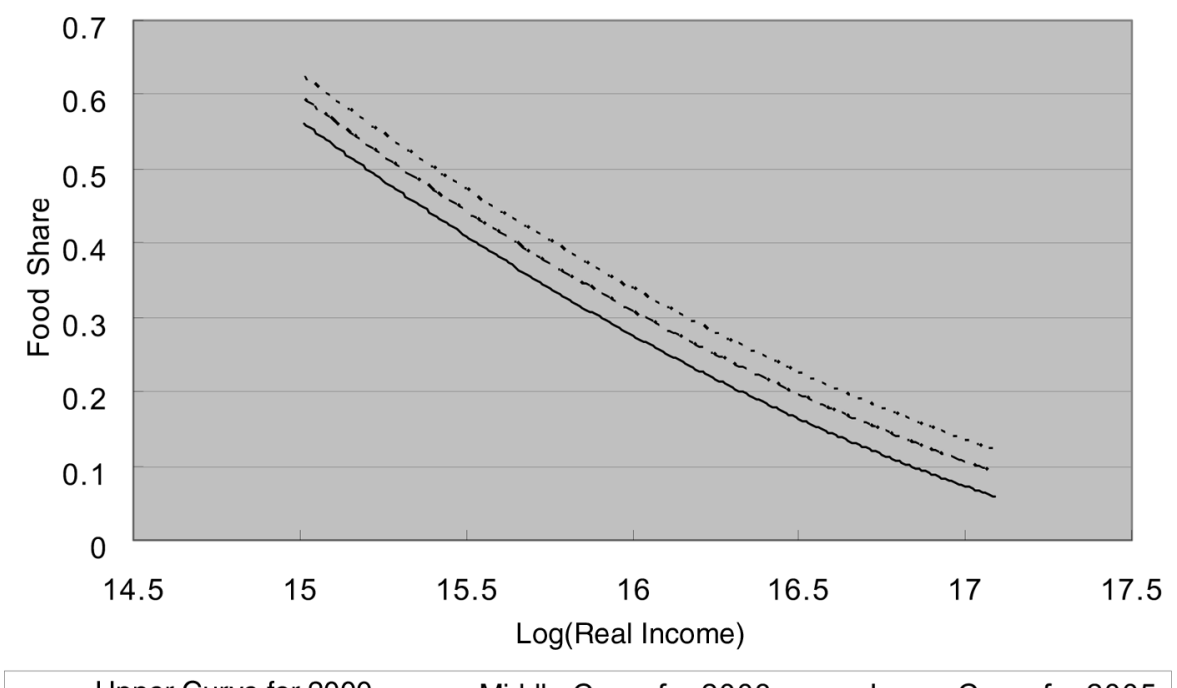

Upper Curve for 2000

Middle Curve for 2003

Lower Curve for 2005

lection criteria are adopted here such as only using households where the food budget share is in the interval $0.01-0.99$. These restrictions are similar to those employed by Hamilton and other studies. The Engel curve relationship should hold for any group of people properly controlling for taste variables and thus a better estimate of CPI bias can be obtained by focusing on a fairly homogeneous group. Furthermore, we also use other control variables to exclude the other sources of the shift of Engel curves over time.

Table 3 contains the results of estimating equation (5) in both a linear and a quadratic form of log real income. Because our data are a genuine panel we can use household fixed effects regression to control for time-invariant unobserved heterogeneity in consumption preferences across the households. The negative coefficients on real income indicate that food budget shares fall as households become richer, which means that food's income elasticity is less than one and this is precisely why food is used as the indicator good here. If the relationship is non-linear, then our linear model estimates will be biased due to an omitted variable bias, and in fact, the linear relationship between log real income and food share is strongly rejected in our data, so we mainly focus on the quadratic model in Table 3.

The estimation results indicate a persistent and substantial downward drift in the food Engel curves. We attribute this drift to unmeasured growth in real expenditures. 
Table 3. Food Engel curve estimations of Korea (KLIPS, 2000-05), obs. $=5,134$

\begin{tabular}{|c|c|c|}
\hline Variable & Linear & Quadratic \\
\hline Intercept & $\begin{array}{c}2.8340 \\
(0.0776)^{\mathrm{c}}\end{array}$ & $\begin{array}{l}15.3146 \\
(0.6875)^{\mathrm{c}}\end{array}$ \\
\hline Log (Real Household Income) & $\begin{array}{l}-0.1544 \\
(0.0037)^{\mathrm{c}}\end{array}$ & $\begin{array}{r}-1.6256 \\
(.0806)^{\mathrm{C}}\end{array}$ \\
\hline$(\log (\text { Real Household Income }))^{2}$ & - & $\begin{array}{c}0.0431 \\
(0.0023)^{\mathrm{c}}\end{array}$ \\
\hline Log (Food CPI/Non-food CPI) & $\begin{array}{c}0.1744 \\
(0.1497)\end{array}$ & $\begin{array}{l}0.3270 \\
(0.1431)^{c}\end{array}$ \\
\hline Number of children under 15 years old in the household & $\begin{array}{c}0.0036 \\
(0.0034)\end{array}$ & $\begin{array}{c}0.0024 \\
(0.0032)\end{array}$ \\
\hline Education Years of Householder & $\begin{array}{c}0.0009 \\
(0.0025)\end{array}$ & $\begin{array}{c}0.0019 \\
(0.0024)\end{array}$ \\
\hline Education Years of Spouse & $\begin{array}{c}-0.00004 \\
(0.0025)\end{array}$ & $\begin{array}{r}-0.0017 \\
(0.0024)\end{array}$ \\
\hline Yearly Hours of Work of Householder & $\begin{array}{c}-3.95 \mathrm{e}-09 \\
(1.58 \mathrm{e}-09)^{\mathrm{b}}\end{array}$ & $\begin{array}{c}-4.48 \mathrm{e}-10 \\
(1.52 \mathrm{e}-09)\end{array}$ \\
\hline Yearly Hours of Work of Spouse & $\begin{array}{c}-2.99 \mathrm{e}-09 \\
(1.38 \mathrm{e}-09)^{\mathrm{b}}\end{array}$ & $\begin{array}{c}-1.91 \mathrm{e}-09 \\
(1.32 \mathrm{e}-09)\end{array}$ \\
\hline Food Expenditure Share out of home & $\begin{array}{c}0.0883 \\
(0.0503)^{\mathrm{a}}\end{array}$ & $\begin{array}{c}0.1375 \\
(0.0480)^{\mathrm{c}}\end{array}$ \\
\hline 2001 Year Dummy & $\begin{array}{c}-0.0112 \\
(0.0043)^{\mathrm{C}}\end{array}$ & $\begin{array}{c}-0.0133 \\
(0.0041)^{\mathrm{c}}\end{array}$ \\
\hline 2002 Year Dummy & $\begin{array}{c}-0.0212 \\
(0.0078)^{\mathrm{c}}\end{array}$ & $\begin{array}{c}-0.0289 \\
(0.0074)^{\mathrm{c}}\end{array}$ \\
\hline 2003 Year Dummy & $\begin{array}{c}-0.0231 \\
(0.0098)^{\mathrm{b}}\end{array}$ & $\begin{array}{c}-0.0338 \\
(0.0093)^{\mathrm{c}}\end{array}$ \\
\hline 2004 Year Dummy & $\begin{array}{c}-0.0397 \\
(0.0169)^{\mathrm{b}}\end{array}$ & $\begin{array}{c}-0.0596 \\
(0.0162)^{\mathrm{c}}\end{array}$ \\
\hline 2005 Year Dummy & $\begin{array}{c}-0.0415 \\
(0.0176)^{b}\end{array}$ & $\begin{array}{c}-0.0622 \\
(0.0168)^{\mathrm{c}}\end{array}$ \\
\hline 2001 Cumulative CPI bias & 0.070 & 0.008 \\
\hline 2002 Cumulative CPI bias & 0.128 & 0.017 \\
\hline 2003 Cumulative CPI bias & 0.139 & 0.020 \\
\hline 2004 Cumulative CPI bias & 0.226 & 0.036 \\
\hline 2005 Cumulative CPI bias & 0.235 & 0.037 \\
\hline & 0.4132 & 0.4664 \\
\hline
\end{tabular}

Note: a. Statistically significant at the 10 percent level. b. Statistically significant at the 5 percent level. $c$. Statistically significant at the 1 percent level. Results on region dummies are omitted.

We have no reason to believe that the nominal income estimates from the KLIPS are becoming increasingly understated in later years of the sample period. Hence, this miscalculation of real expenditures is attributed to CPI bias. We estimate that over the 6 years from 2000 to 2005, the cumulative bias in the Korean CPI is between 0.037 and 0.235 , depending on the estimation method. Both of these estimates are statistically significantly different from zero. This range corresponds to an average annual bias of between 0.7 and 4.5 percentage points. The lower and more reliable values come from the non-linear estimates. Based on the lower value, at least one-fifth of the measured rise in the cost of living can be attributed to CPI bias. 


\section{Implications of CPI bias for economic management and theories}

\section{I CPI bias on economic management in Korea}

It is crucial to measure the CPI precisely for the accurate evaluation of a country's economic progress. When there is an upward bias in the CPI, some macroeconomic variables, such as real GDP as an indicator of living standards, can be understated. Those mismeasured economic indicators may not reflect true conditions of the economy, and consequently, they may lead to imprudent economic policies. Examples include ineffective inflation targeting for monetary policy and possibly social payment programs that result in unintended and undue transfers from one group to another group in the economy.

For monetary policy, if there are overstated changes in prices, policymakers are more often forced to pursue tight policies to reduce the rate of inflation. Indeed the possibility of a CPI bias is one of several reasons for inflation-targeting central banks to have a positive rather than zero target rate of inflation. However, because there have not been previous measures of the CPI bias for Korea, it has not been possible to debate whether monetary policy efforts to reduce measured CPI inflation have been excessive and might induce undue sacrifices like a higher unemployment rate, at least according to the view from the short-run Phillips curve.

For public transfers, when there is an upward CPI bias and the public pension is indexed to the inflation rate, the government will inadvertently transfer resources from the younger generation to the elderly. Currently, measured inflation (as the change in the CPI) is used to index pension payments in Korea. In 2005, the various pension payments in Korea are up to US\$ 9 billion per year and the share of GDP for these payments is rising rapidly due to the large baby boom generation, which, as in the United States, is reaching retirement age. In fact, the total pension payment is expected to double by 2015. For the next 5 years, the estimated bias in the Korean CPI will induce undue pension payments of more than 0.01 percent of GDP annually.

\subsection{CPI bias in a small open economy}

The GDP deflator measured by the ratio of nominal GDP to real GDP provides different information about the change in true price levels in the economy. In general, $\mathrm{CPI}$ as a Laspeyres index is likely to overstate the true increase in the cost of living and the GDP deflator, such as a Paasche index, is likely to understate it. One of the key differences is that the GDP deflator does not include the imported goods consumed by consumers. For the last decade, imports into Korea from China have increased immensely, especially in agricultural products. These imports have had substantial impacts on the Korean economy. In particular, the prices of food products 
have been maintained at low levels due to cheap agricultural products from China and the imported goods might bring deflation for some products as in the phenomenon of Japan (Broda and Weinstein 2007). Here, we extend our discussion to incorporate changes in exchange rates into the analysis. In doing so, we investigate the relationship between the size of CPI bias and whether an economy is small and open, and hence, more responsive to trade shocks, which results in volatile relative prices and a larger substitution bias in the CPI than for that of large economies like the United States. Since 2000, the Korean CPI has increased by 23.5 percent and GDP deflator increased by only 11.2 percent. ${ }^{9}$ The pattern confirms the predicted biases from the Laspeyres and Paasche indexes, but the size of the difference is much greater than those of other large countries like the United States. This large difference also justifies our discussion on CPI bias in a small open economy.

As a small open economy, Korea often faces large variations in exchange rates. When there are some discrepancies between the prices of imported goods (which are highly responsive to varying exchange rates) and local goods, consumerpurchasing decisions in the market may change faster than changes occur in the basket of goods used in the calculation of the CPI. Hence, these discrepancies could be a source of Korea's substantial CPI bias. Indeed, the size of the CPI bias appears to be sensitive to having real income adjusted by the exchange rate, with a considerable fall in the calculated bias (Table 4). As in Table 4, when we re-estimate equation (5) with real income adjusted by the changes in exchange rates, the cumulative bias in the Korean CPI during the sample period is 0.028 and 0.15 , depending on the estimation method. Results indicate approximately one-third of the CPI bias can be attributed to some discrepancies between the changes in imported goods and prices and the changes in goods and prices used in formation of CPI. This confirms Gibson's (2008) finding of a substantial CPI bias in a small open economy like New Zealand, which is likely to be more responsive to trade shocks and have a stronger substitution bias than that of large economies like the United States.

\subsection{Implications of CPI bias on economic theories of business cycles}

If the estimated CPI bias in the previous section is to overstate the true increases in prices, then the growth of real GDP is to be understated. Analogously, real wage growth is also to be understated. Therefore, we consider implications of this understated real wage growth on economic theories, which play an important role in determining appropriate economic policies for business cycles.

9 For the three decades before 2000, GDP deflator increased more rapidly than CPI and the pattern is reversed after 2000. This interesting pattern needs an explanation, and we plan to investigate it in an extended work. 
Table 4. Food Engel curve estimations of Korea with real income adjusted by exchange rates (KLIPS, 2000-05), obs. = 5,134

\begin{tabular}{|c|c|c|c|c|}
\hline & \multicolumn{2}{|c|}{ Linear } & \multicolumn{2}{|c|}{ Quadratic } \\
\hline & & $\begin{array}{l}\text { Adjusted real income } \\
\text { by exchange rate }\end{array}$ & & $\begin{array}{l}\text { Adjusted real income } \\
\text { by exchange rate }\end{array}$ \\
\hline 2001 Cumulative CPI bias & 0.070 & 0.085 & 0.008 & 0.009 \\
\hline 2002 Cumulative CPI bias & 0.128 & 0.099 & 0.017 & 0.014 \\
\hline 2003 Cumulative CPI bias & 0.139 & 0.085 & 0.020 & 0.014 \\
\hline 2005 Cumulative CPI bias & 0.235 & 0.151 & 0.037 & 0.028 \\
\hline
\end{tabular}

Note: The share of imported goods is assumed to be 0.5 .

As an example of the type of economic theories that can be affected by the understated real wage growth, we can consider a fixed effects model of earnings transitions, as in the following: ${ }^{10}$

$$
y_{i t}=y_{i t}^{P}+y_{i t}^{T}-p_{t}=\left(\alpha_{i}+\gamma_{1} X_{i t}+\gamma_{2} X_{i t}^{2}\right)+\left(\beta U_{1}+\varepsilon_{i t}\right)-p_{t}
$$

where $y_{i t}$ is the $i^{\text {th }}$ worker's log real annual earnings in year $t, y_{i t}^{p}$ is the permanent component, and $y_{i t}^{T}$ is the transitory component, which can be affected by a business-cycle or just individual specific transitory events, and $p_{t}$ is $\log$ CPI in year $t$, the fixed effect $\alpha_{i}$ represents the combined effect of time-invariant characteristics of worker $i, X_{i t}$ is worker $i$ 's years of work experience as of year $t, U_{t}$ is a business-cycle indicator such as the unemployment rate or real GDP, and $\epsilon_{i t}$ is an individual transitory fluctuation. If we are interested in the transitions of real annual earnings due to either the permanent factor or the transitory factor, then we may first-difference equation (5) to get

$$
\Delta y_{i t}=\delta_{0}+\delta_{1} X_{i t}+\beta \Delta U_{t}+\Delta \epsilon_{i t} .
$$

When interested in whether earnings vary counter-cyclically, non-cyclically, or procyclically with the business cycle, one can investigate the sign of $\beta$. However, instead of true real wage growth, we use dependent variables with non-classical errors-in-variables due to the CPI bias like:

$$
\Delta y_{i t}^{*}=\Delta y_{i t}^{p}+\Delta y_{i t}^{t}-\Delta p_{t}^{*}=\Delta y_{i t}^{p}+\Delta y_{i t}^{t}-\pi_{t}-\varepsilon_{\tau}=\lambda \Delta y_{i t}
$$

where $\pi_{t}$ represents the cumulative percentage increase in the true price from period $t$ to period $t+1$ and $\epsilon_{t}$ is the percent cumulative measurement error in the CPI.

10 This fixed effect model follows the specification used in Kim and Solon (2005). 
What does this imply for the estimation of cyclicality in real earnings? Substituting equation (10) into equation (9) yields

$$
\Delta y_{i t}^{*}=\lambda\left(\delta_{0}+\delta_{1} X_{i t}\right)+\lambda \beta \Delta U_{t}+\lambda \Delta \varepsilon_{i t} .
$$

The coefficient of $\Delta U_{t}$ is not the original wage cyclicality parameter $\beta$, but rather $\beta$ rescaled by the CPI bias parameter $\lambda$. More broadly, the mean reversion in dependent variables like our model will tend to make estimated regression coefficients too small in magnitude, which is contrary to the textbook case where errors in the dependent variable cause no bias in slope coefficients. This (mean-reverting) measurement error in real wage growth may lead to as much as a 25 percent underestimation of pro-cyclicality of real wages. This result could misguide policymakers in their understanding of business cycles and might lead them to an inadequate choice of economic policies for business cycles.

\subsection{Policy suggestions}

To improve the quality of the Korean CPI, KNSO may consider what the BLS of the United States has done already. Subsequent to the Boskin Report, the BLS introduced methodological changes that can address the substitution, quality, and new goods issues. According to Johnson, Reed, and Stewart (2006, p. 10),

These include the following: 1) the introduction of the geometric means formula to account for lower-level substitution, 2) the introduction of the Chained Consumer Price Index for All Urban Consumers (C-CPI-U) to provide an index that accounts for upper-level substitution, 3) expansion of the use of hedonic models to improve the measurement of quality change, and 4) the institution of procedures to introduce new goods into the index more quickly by more frequent updates to the item samples.

The estimates of CPI bias for Korea reported in the current paper, and the various economic implications of this bias, suggest that it is a matter of some urgency for improvements to be made to the Korean CPI so that it provides a better basis for evaluating economic progress in Korea.

\section{References}

Boskin, Michael J., Ellen R. Dulberger, Robert J. Gordon, Zvi Griliches, and Dale W. Jorgenson. 1996. Final Report of the Advisory Commission to Study the Consumer Price Index. Washington, DC: U.S. Government Printing Office.

Broda, Christian, and David E. Weinstein. 2007. Exporting Deflation? Chinese Exports and Japanese Prices. Working paper. Chicago, IL: University of Chicago. 
Chung, Chul, Bonggeun Kim, and Myungho Park. 2007. CPI Bias in Korea. Journal of International Economic Studies 11 (2):261-284.

Costa, Dora L. 2001. Estimating Real Income in the United States from 1888 to 1994: Correcting CPI Bias Using Engel Curves. Journal of Political Economy 109 (6):1288-1310.

Deaton, Angus S., and John Muellbauer. 1980. An Almost Ideal Demand System. American Economic Review 70 (3):312-326.

Gibson, John K. 2008. Using Engel Curves to Estimate CPI bias in a Small, Open, InflationTargeting Economy. Working paper. Hamilton: University of Waikato.

Gibson, John K., Steven Stillman, and Trinh Le. 2008. CPI Bias and Real Living Standards in Russia During the Transition. Journal of Development Economics 87 (1):140-160.

Gordon, Robert J., and Todd vanGoethem. 2005. A Century of Housing Shelter Prices: How Big is the CPI Bias? NBER Working Paper No. 11776. Cambridge, MA: National Bureau of Economic Research.

Hamilton, Bruce W. 2001. Using Engel's Law to Estimate CPI Bias. American Economic Review 91 (3):619-630.

Johnson, David S., Stephen Reed, and Kenneth J. Stewart. 2006. Price Measurement in the United States: A Decade After the Boskin Report. Monthly Labor Review 129 (5):10-19.

Kim, Bonggeun, and Gary R. Solon. 2005. Implications of Mean-Reverting Measurement Error for Longitudinal Studies of Employment and Wages. Review of Economics and Statistics 87 (1):193-196.

Korea National Statistical Office. www.nso.go.kr

Reinsdorf, Marshall, and Jack E. Triplett. 2009. A Review of Reviews: Ninety Years of Professional Thinking about the Consumer Price Index and How to Measure It. In Price Index Concepts and Measurement, Studies in Income and Wealth, vol. 70, edited by W. Erwin Diewert, John Greenlees, and Charles R. Hulten, 17-84. Chicago, IL: The University of Chicago Press for the National Bureau of Economic Research. 